\title{
Larval development of Microgobius tabogensis Meek \& Hildebrand, 1928 (Pisces: Gobiidae) from a coastal lagoon in the Gulf of California, México
}

\author{
Enrique A. González-Navarro ${ }^{1}\left(\mathbb{D}\right.$, Ricardo J. Saldierna-Martínez ${ }^{2}(\mathbb{D})$ \& Gerardo Aceves-Medina ${ }^{2}$ \\ ${ }^{1}$ Departamento de Biología Marina, Universidad Autónoma de Baja California Sur \\ La Paz, Baja California Sur, México \\ ${ }^{2}$ Instituto Politécnico Nacional, Centro Interdisciplinario de Ciencias Marinas \\ Departamento Plancton y Ecología Marina, La Paz, Baja California Sur, México \\ Corresponding author: Gerardo Aceves-Medina (gaceves@ipn.mx)
}

\begin{abstract}
In fish, the larval stage constitutes the most vulnerable phase in the life cycle and reveals important ecological and evolutive information of fish and fundamental data to manage marine ecosystems. However, their identity is one of the biggest gaps in knowledge, particularly for the Microgobius genus, where only three of 15 species have been described. In this study, the larval development of Microgobius tabogensis was described based on 116 specimens (2.75-14.20 mm standard length) from Ensenada de La Paz, Mexico. The typical gobiid body shape characterized larvae, a well-developed dorsally pigmented gas bladder, a curve at the hindgut, and 27 myomeres. The pigmentation pattern in M. tabogensis consisted of a series of melanophores along the ventral postanal midline, increasing from three to seven during the preflexion stage and up to 16 in the postflexion stage. It had three to five melanophores on the ventral preanal midline, one at the jaw angle and one on the dorsal postanal midline. Through all stages, one of the ventral melanophores was normally stellate, bigger than the others, and extended between the myomeres. A dorsal melanophore was located near the end of the intestine in the preflexion stage but disappeared with growth. Notochord flexion started at approximately $4.3 \mathrm{~mm}$ and ended at $5.1 \mathrm{~mm}$. Anal fin development started at the beginning of the flexion stage, followed by the dorsal fin. All elements of the fins were formed by the late postflexion stage (14.2 $\mathrm{mm})$.
\end{abstract}

Keywords: Microgobius tabogensis; Gobiidae; larval development; coastal lagoon; Gulf of California

\section{INTRODUCTION}

Ichthyoplankton studies have become important in fisheries, oceanography, and systematic research since they are used in the evaluation of fishing resources, breeding, and spawning areas or seasons and provide essential information about factors influencing the recruitment of populations of ecologic or economic interest (Aceves-Medina et al. 2020, Zacardi et al. 2020). Gobiidae is a taxonomic group of high ecological interest since it is one of the marine fish family with the most species. Together with clinids and blenniids, it comprises the dominant elements of the benthonic fauna along tropical coasts. However, due to their small size and often cryptic ecologies, the full extent of gobiid diversity usually goes unnoticed and has hindered evolutionary and taxonomic studies of the group (Thacker \& Roje 2011). There are about 200 gobiid genera with nearly 1500 described species, but there might be as many as 2000 species (Patzner et al. 2011, Thacker \& Roje, 2011, Agorreta et al. 2013). Although advances in molecular phylogenetics have provided a novel avenue for untangling gobioid relationships (Thacker \& Hardman 2005, Thacker \& Roje 2011), new studies have shown that chromatophore and pigmentation patterns of marine gobiid larvae could be a novel ontogenetic character suite worthy of further study (Baldwin \& Smith 2013).

The family Gobiidae consists of small marine and freshwater fish, primarily tropical and subtropical.

Corresponding editor: Sergio Palma 
Gobies typically have joined pelvic fins that form a sucking disk in most species. They have cycloid or ctenoid scales (or none) and lack a lateral line. Microgobius Poey, 1876 belongs to the American seven-spined gobies, Gobiosomatini tribe (Smith \& Baldwin 1999), characterized by having seven spines in the first dorsal fin and hypural bones (1 and 2) that are not fused to the urostyle. The genus comprises 15 species distributed in different habitats, from lowsalinity estuaries to coral reefs of the western Atlantic and eastern Pacific Oceans. Most species display strong sexual dimorphism. The dorsal spines are frequently elongated into filaments (usually only in the males) and have a pterygiophore pattern of 3-221110 (Birdsong et al. 1988). Six Microgobius species are present in the northwest region of the Mexican Pacific, including the Gulf of California (Birdsong 1981): M. brevispinis Ginsburg, 1939; M. cyclolepis Gilbert, 1890; M. emblematicus (Jordan \& Gilbert, 1882); M. erectus Ginsburg, 1938; M. miraflorensis Gilbert \& Starks, 1904; and M. tabogensis Meek \& Hildebrand, 1928. M. tabogensis differs from the other species of this genus by having a modal count of 17 elements in both the second dorsal and anal fins, a fleshy nuchal crest in females (absent in males), dorsal spines two through five are transformed into elongate filaments in both sexes. Seven to nine teeth in the outer row of the dentary. The distribution range of those species is from the lower west coast of the Baja California Peninsula and the Gulf of California to Colombia, mostly in mangroves with muddy-sand bottoms (Birdsong 1981).

Although Gobiidae larvae are frequently among the most abundant and diverse taxa in ichthyoplankton studies around the world (e.g. Urias-Leyva et al. 2018, Guyah et al. 2021), only about 5\% of the gobiids have been observed in their larval stage, most of which were from Japanese waters (Ruple 1984). Most descriptions are limited to recently hatched larvae or postflexion stages (Matarese et al. 1989, Watson 1996, Baldwin \& Smith 2003, Yeung \& Ruple 2006). Only a few species have been described through their whole larval development (e.g. Zavala et al. 1988, Watson 1996, Yeung \& Ruple 2006, Tran et al. 2018). As is the case of the genus Microgobius, only M. thalassinus, $M$. gulosus, and M. meeki have been described throughout their complete larval phase (Hildebrand \& Cable 1938, Richardson \& Joseph 1975, Fritzsche 1978, Teixeira de Farias 2017).

Gobiidae larvae at the mouth of the Ensenada de La Paz seem to have an important ecological role since they are very abundant and frequent and present a considerable diversity of unidentified forms (e.g. Aceves-Medina et al. 2008). Although important efforts have been made in the description of fish larvae for various taxonomic groups in the area, of the 21 morphotypes of gobiid deposited in the ichthyoplankton collection (INE-SEMARNAT, B.C.S. PEC. 089.0300) of the Centro Interdisciplinario de Ciencias Marinas (CICIMAR), Instituto Politécnico Nacional, only Evermannia zosterura has been described throughout all its larval stages (González-Navarro et al. 2014). The objective of this work was to identify to the species level the larvae of a morphotype of the Gobiidae family deposited in the "Ictioplancton" collection at CICIMAR, using a development series from preflexion to postflexion stages, which was built based on a very constant pigmentation pattern. Based on these specimens, the main characteristics that allowed identifying these larvae at each one of their larval developmental stages (preflexion, flexion, and postflexion) were described and differentiate them from the described species of this genus in the Atlantic and Pacific, as well as from similar species in the northeastern Pacific.

\section{MATERIALS AND METHODS}

From April 1991 through May 1992, a series of zooplankton samples were obtained from Ensenada de La Paz, B.C.S., Mexico. Surface trawls were done at 2 $\mathrm{kn}$ with a conical net of $0.6 \mathrm{~m}$ in mouth diameter, $2 \mathrm{~m}$ in length, and $250 \mu \mathrm{m}$ mesh size to collect fish larvae. In June and July 1992, an epibenthic net with a rectangular mouth of $0.6 \mathrm{~m}$ wide $\times 0.4 \mathrm{~m}$ high, $3 \mathrm{~m}$ in length, and $1 \mathrm{~mm}$ mesh size was towed at $31 \mathrm{~m} \mathrm{~min}^{-1}$ over the bottom to collect juveniles and postflexion larvae. All samples were fixed immediately with sodium borate-buffered 5\% formalin, and the specimens were subsequently removed and stored in 3\% borate-buffered formalin.

Fish larvae and juveniles with 27 myomers and the same morphology and pigmentation pattern were sorted from the samples with a stereomicroscope and identified as a Gobiidae morphotype according to Watson (1996). The pigmentation pattern remained with low variation through early preflexion to late postflexion stages and early juveniles and was not described in any other Gobiidae species as larvae.

Five organisms, including four adults (26.1-34.21 $\mathrm{mm}$ standard length, SL) and one juvenile (16.5 mm SL) that presented the same number of elements in the dorsal, anal, and caudal fins as the late stages of the Gobiidae morphotype, as well as four larvae from the early to the late postflexion stage (9.3 to 11.71-12.76 $\mathrm{mm} \mathrm{SL}$ ), were selected. A clear and stain technique was applied (Potthoff 1984), and samples were identified as Microgobius tabogensis based on their meristic characteristics described by Birdsong (1981) and 
Table 1. Meristic characteristics of Microgobius spp. from the northern region of the Mexican Pacific, including the Gulf of California (Birdsong 1981).

\begin{tabular}{lccccc}
\hline Species & Dorsal fin rays & Anal fin rays & $\begin{array}{c}\text { Pectoral } \\
\text { fin rays }\end{array}$ & $\begin{array}{c}\text { Dentary } \\
\text { teeth }\end{array}$ & $\begin{array}{c}\text { Gill } \\
\text { rakers }\end{array}$ \\
\hline M. brevispinis & VII+ I, 15-18(17) & $\mathrm{I}, 15-18(17)$ & $19-22(21)$ & $6-7$ & $4+16$ \\
M. cyclolepis & VII+ I, 14-16(15) & $\mathrm{I}, 15-16(15)$ & $22-24(23)$ & $6-8$ & $5+16$ \\
M. emblematicus & VII+ I, 15-17(16) & $\mathrm{I}, 15-17(16)$ & $18-23(20)$ & $4-5$ & $4+16$ \\
M. erectus & VII+ I, 13-14(14) & $\mathrm{I}, 13-14(14)$ & $20-23(23)$ & $6-8$ & $3+13$ \\
M. miraflorensis & VII+ I, 15-17(16) & $\mathrm{I}, 15-17(16)$ & $20-23(21)$ & $15-20$ & $4+15$ \\
M. tabogensis & VII+ I, 15-17(16) & $\mathrm{I}, 15-17(16)$ & $19-23(22)$ & $7-9$ & $4+13$ \\
\hline
\end{tabular}

listed in Table 1. The external and osteological morphology of the cleared and stained postflexion larvae and their meristic and pigmentation patterns were used to obtain a developmental series of 116 specimens. Each larva was assigned to a developmental stage based on the grade of their notochord flexion (preflexion, flexion, or postflexion) and the presence of scales (juvenile), according to Ahlstrom et al. (1976).

The specimens were examined under a stereomicroscope equipped with an ocular micrometer to describe each developmental stage and document the main characteristics that allowed identification through all larval stages. Counts and measurements (to the nearest $0.05 \mathrm{~mm}$ ) were made on the left side of the specimen. The following measurements were taken: SL, from the tip of the snout to the end of the notochord or in more developed larvae, to the base of the caudal rays; head length (HL), from the tip of the snout to the cleithrum margin in small specimens or from the tip of the snout to the opercular margin in larger ones; eye diameter (ED), the maximum horizontal distance measured from the anterior to the posterior margin of the eye; preanal length (PrL), from the tip of the snout along the midline to a vertical line from the anus; pectoral body depth (BDp), depth of the body perpendicular to the body axis, excluding the fin-fold, at the pectoral symphysis; swim bladder length (SBL), from the tip of the snout to the beginning of the swim bladder. To determine if larval growth was iso- or allometric, we calculated the body proportions concerning SL and HL. A one-way analysis of variance (ANOVA) or its non-parametric Kruskal-Wallis equivalent was performed in ( $\mathrm{R}$ Core Team 2016), depending on whether they met the normality assumptions homoscedasticity. Before statistical analysis, we used the Kolmogorov-Smirnov method to test if data had a normal distribution.

\section{RESULTS}

A distinctly different morphotype was separated from the rest of the collected specimens from all gobiidshaped larvae obtained from the zooplankton samples. This group of larvae was characterized by 27 total myomers and a pigmentation pattern with a small variation from the preflexion to posflexion stage. This pattern consisted of one melanophore over the lower jaw angle, a well-developed dorsally pigmented swim bladder, a series of postanal melanophores along the anal-fin base that formed a double row along the sides of the base as it formed, and one of those melanophores was stellate and bigger and was always located at postanal myomere 10. One melanophore was located on the lower part of the caudal fin base that usually took the shape of a patch. The combination of all these pigmentation characteristics had not yet been recorded in any other gobiid species, and the low variation found in this pattern suggested one specific taxonomic morphotype.

With the development series of the Gobiidae morphotype, the postflexion larvae and the juveniles and adults with the same elements of the dorsal, anal, and pectoral fins were cleared and stained to observe the osteological characteristics according to Pothoff's (1984) technique. Once it was possible to visualize the internal meristic characteristics, the taxonomic criteria used to identify Microgobius tabogensis were the number of teeth in the external row of the dentary, the number of gills rakers, and the fin ray counts (Birdsong 1981). Cleared and stained postflexion, juveniles, and adults from 9.3-34.21 mm SL ( $\mathrm{n}=9)$ had hypural bones (1 and 2) that were not fused to the urostyle as a diagnostic characteristic of Microgobius (Fig. 1a). All specimens had 11 precaudal and 16 caudal vertebrae, VII+I, 15-16 dorsal fin formula, I, 15-16 anal fin formula (Fig. 1c), and 20-22 pectoral rays, the mode of the spinous pterygiophores pattern was 3-221110 for the dorsal-fin (Fig. 1b), and 211112112121 in the anal 

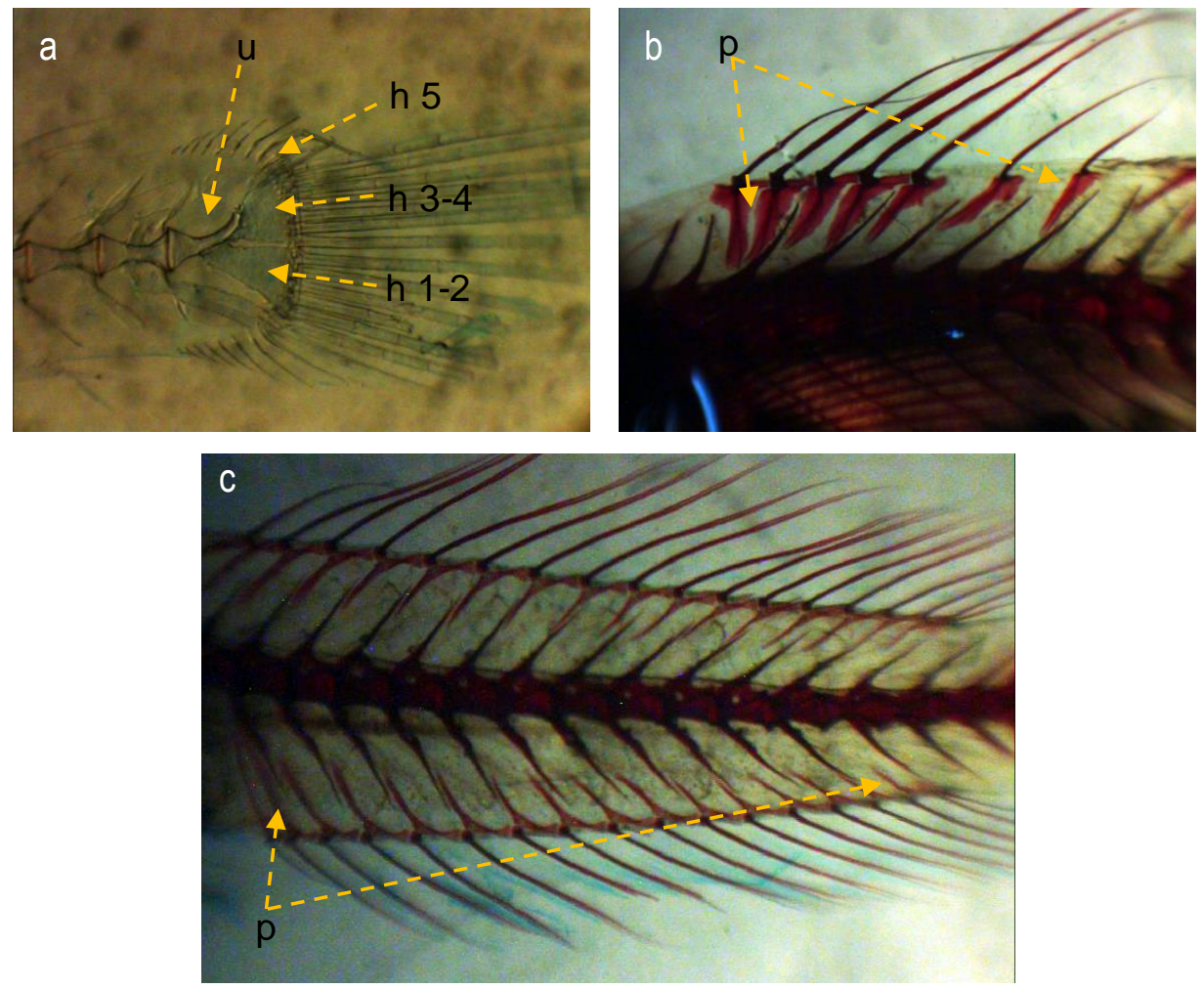

Figure 1. Microgobius tabogensis. a) Caudal fin, b) first dorsal fin, c) second dorsal fin and anal fin. u: urostyle, h: hypural bones, p: pterigyophores.

fin (Fig 1c). There were 7-9 dentary teeth (juvenile stage) and 13-gill rakers (juvenile stage).

\section{Distinctive characteristics of Microgobius tabogensis}

Larvae are elongate with a preanal length of ca. $45-60 \%$ of SL. They have a prominent swim bladder located over the gut in their middle region. The intestine is straight in its first two-thirds throughout larval development and curved at the hindgut, accentuated in the preflexion stage (Fig. 2). The pigmentation pattern consists of a well-developed dorsally pigmented swim bladder (Figs. 2a-c). A series of three to 16 postanal melanophores along the anal-fin base form a double row along the sides of the base as it forms; one of them is stellate and bigger and is always at postanal myomere 10 (Figs. 2a-d). This melanophore becomes internal between the adjacent myosepta during development. There are three to five preanal melanophores on the ventral midline of the gut and one on the lower jaw angle (Figs. 2a-d). There is a melanophore in the hindgut near the point where it deviates downward during preflexion, which later in development persists but is not externally visible. There is another melanophore on the dorsal midline of the tail (Fig. 2a). When present, the melanophore is opposite the enlarged melanophore on the ventral midline of the tail, which is not observed during flexion. The smallest larvae had no trace of yolk, so their hatching size is probably smaller. Preflexion, flexion, and postflexion larvae were between 2.75-4.25, 4.3-5.1 (Table 2), and 5.2-14.2 mm SL (Table 3), respectively.

\section{Morphology}

Larvae have morphology typical of gobiid larvae. They are elongated-compressed with horizontally elongate eyes from the preflexion to flexion stage and round eye in postflexion. They lack the fold in the hindgut typical of the eleotrids and the scarids' anterior gut fold and gut rugosity characteristic. Preanal length is ca. $45-60 \%$ of SL, with the gut reaching half the body length throughout development. Body proportions remained constant during development. The relative proportion of the HL/SL, PrL/SL, and BDp/SL was not statistically different between the preflexion and postflexión stages (Table 4). However, larval growth was allometric for $\mathrm{ED} / \mathrm{HL}$, decreasing from preflexion to postflexion $(P<$ $0.05)$, and SBL/SL increases from preflexion to postflexion $(P<0.05)$ (Table 4$)$.

\section{Pigmentation}

Preflexion larvae $(\leq 4.3 \mathrm{~mm}$ SL) have a well-developed dorsally pigmented swim bladder and one melanophore in the lower angle of the jaw; both characteristics persist 

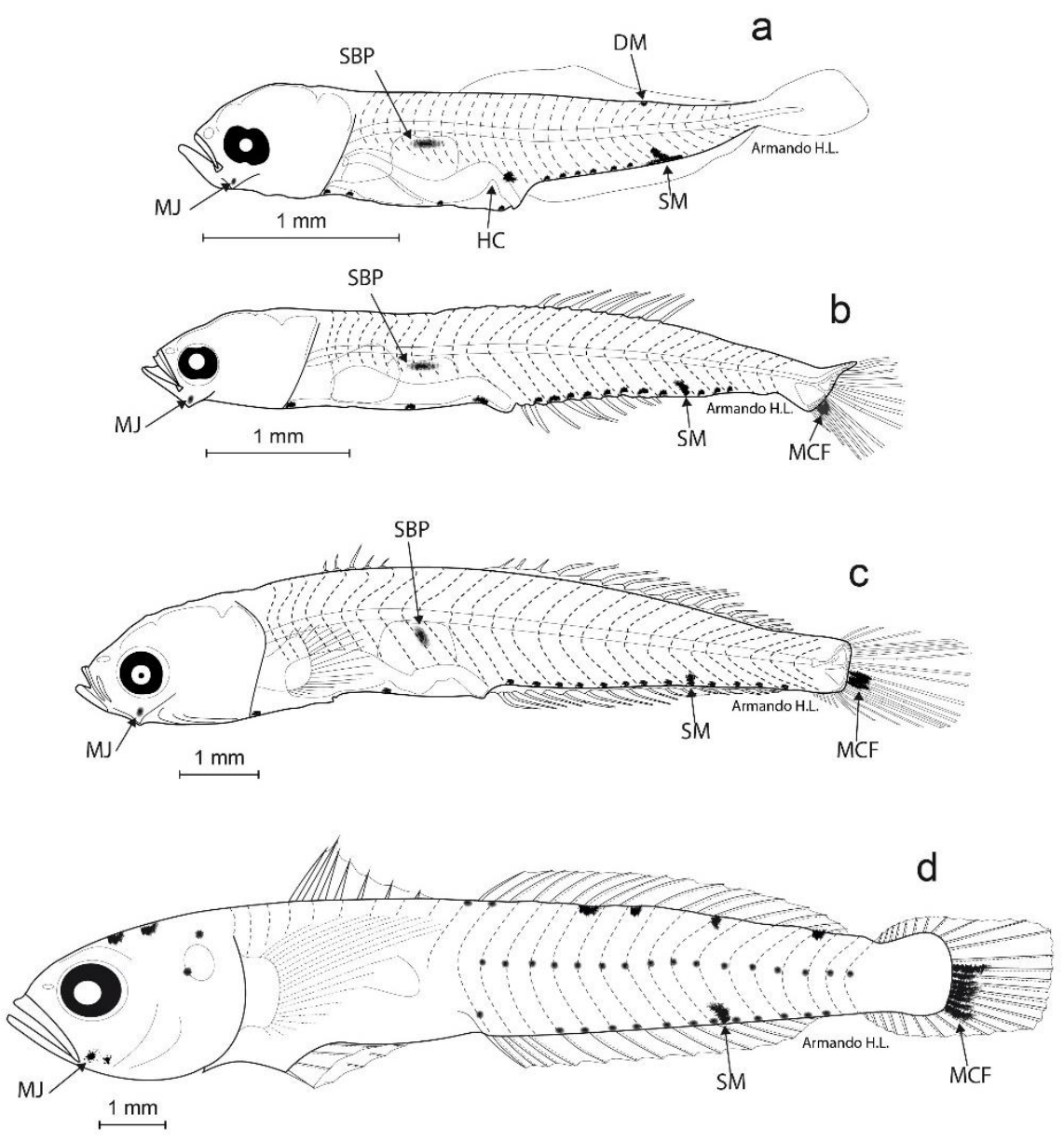

Figure 2. Microgobius tabogensis larvae. a) Preflexion larva (at $3.5 \mathrm{~mm}$ standard length, SL), b) flexion larva (at $4.8 \mathrm{~mm}$ $\mathrm{SL}$ ), c) postflexion larva (at $9.6 \mathrm{~mm} \mathrm{SL}$ ), d) late postflexion larva (at $14.2 \mathrm{~mm} \mathrm{SL}$ ). MJ: melanophores on the lower jaw angle, SBP: dorsally pigmented swim bladder, HC: hindgut curve, DM: melanophore dorsal, SM: melanophore stellate and bigger, MCF: melanophore on the lower part of the caudal fin base.

throughout larval development (Fig. 2a). They have three to seven melanophores on the ventral midline of the tail that are sometimes fused, forming a continuous line. One ventral melanophore is always located at the postanal myomere 10 , which is normally stellate, bigger than the others, and may extend onto the adjacent myosepta. There are three to five ventral melanophores between the isthmus and anus, one melanophore on the dorsal midline, approximately midway between the anus and the notochord tip (caudal myomere 10), one dorsally on the hindgut, and one over the lower angle of the jaw (Fig. 2a).

During the flexion stage (4.3-5.1 mm SL), the pigmentation pattern remains almost the same as in the preflexion stage. In addition, the number of postanal melanophores of the tail increases up to 10 along the anal-fin base, forming a double row along the sides of the base as it forms; the stellate one remains, and the dorsal melanophore on the hindgut and the one on the dorsal midline may remain or disappear. At the end of the flexion stage, a melanophore is present on the lower part of the caudal fin base (Fig. 2b).

During the postflexion stage (5.2-14.2 $\mathrm{mm} \mathrm{SL}$ ), the number of postanal melanophores in the double row along the anal-fin base increases up to 16 , and the stellate one is still present. The melanophore over the lower jaw angle and those on the ventral preanal midline remains, but they were not evident in some specimens. The melanophore on the caudal fin usually takes the form of a patch. One melanophore in the otic vesicle region is also present during this stage (Fig. 2d). Near the end of this stage $(\sim 14.2 \mathrm{~mm} \mathrm{SL})$, the stellate melanophore may remain external or entirely internal but visible (Fig. 2d). Three series of melanophores occur on the body: the first (about 14 melanophores) along the postanal ventral midline, forming a double row along the sides of the anal-fin base; the second 
Table 2. Measurements ( $\mathrm{mm})$ and the number of preanal (PrA) and postanal (PoA) myomers of preflexion and flexion larvae of Microgobius tabogensis. SL: standard length, HL: head length, ED: eye diameter, PrL: preanal length, BDp: pectoral body depth, SBL: swim bladder length.

\begin{tabular}{|c|c|c|c|c|c|c|c|c|c|c|c|c|c|c|c|}
\hline \multicolumn{6}{|c|}{ Preflexion stage } & \multicolumn{2}{|c|}{ Myomers } & \multicolumn{6}{|c|}{ Flexion stage } & \multicolumn{2}{|c|}{ Myomers } \\
\hline SL & $\mathrm{HL}$ & ED & PrL & $\mathrm{BDp}$ & SBL & $\operatorname{PrA}$ & PoA & SL & HL & ED & PrL & BDp & SBL & PrA & PoA \\
\hline 2.75 & 0.6 & 0.2 & 1.3 & 0.45 & 0.8 & 11 & 16 & 4.3 & 1 & 0.3 & 2.3 & 0.7 & 1.5 & 12 & 15 \\
\hline 3.05 & 0.7 & 0.3 & 1.6 & 0.55 & 0.9 & 11 & 16 & 4.3 & 1.1 & 0.3 & 2.6 & 0.65 & 1.6 & 12 & 15 \\
\hline 3.25 & 0.8 & 0.3 & 1.7 & 0.6 & 1 & 12 & 15 & 4.35 & 1.1 & 0.3 & 2.5 & 0.7 & 1.6 & 12 & 15 \\
\hline 3.35 & 0.9 & 0.3 & 1.7 & 0.6 & 1.2 & 12 & 15 & 4.4 & 1.1 & 0.4 & 2.3 & 1.05 & 1.6 & 12 & 15 \\
\hline 3.4 & 1 & 0.3 & 1.8 & 0.6 & 1.2 & 12 & 15 & 4.4 & 1 & 0.3 & 2.3 & 0.7 & 1.5 & 12 & 15 \\
\hline 3.4 & 0.9 & 0.2 & 1.7 & 0.65 & 1.1 & 12 & 15 & 4.4 & 1.1 & 0.3 & 2.3 & 0.65 & 1.5 & 12 & 14 \\
\hline 3.4 & 0.9 & 0.3 & 1.8 & 0.6 & 1.2 & 12 & 15 & 4.5 & 1 & 0.3 & 2.4 & 0.75 & 1.7 & 12 & 15 \\
\hline 3.45 & 0.7 & 0.3 & 1.9 & 0.6 & 1.2 & 12 & 15 & 4.5 & 1 & 0.3 & 2.4 & 0.6 & 1.6 & 12 & 15 \\
\hline 3.6 & 0.8 & 0.3 & 2 & 0.65 & 1.3 & 12 & 15 & 4.6 & 1.1 & 0.3 & 2.6 & 0.7 & 1.6 & 12 & 15 \\
\hline 3.65 & 0.9 & 0.3 & 1.9 & 0.6 & 1.3 & 11 & 16 & 4.6 & 1.2 & 0.3 & 2.5 & 0.7 & 1.6 & 12 & 15 \\
\hline 3.75 & 0.9 & 0.3 & 1.9 & 0.65 & 1.3 & 12 & 15 & 4.65 & 1.2 & 0.4 & 2.6 & 1.15 & 1.9 & 12 & 15 \\
\hline 3.9 & 0.9 & 0.3 & 2.2 & 0.85 & 1.3 & 12 & 15 & 4.75 & 1.1 & 0.3 & 2.5 & 0.75 & 1.8 & 10 & 17 \\
\hline 3.9 & 1 & 0.3 & 2 & 0.6 & 1.3 & 12 & 15 & 4.75 & 1.1 & 0.3 & 2.5 & 0.75 & 1.9 & 12 & 15 \\
\hline 3.9 & 0.9 & 0.3 & 2 & 0.65 & 1.6 & 12 & 15 & 4.8 & 1.1 & 0.3 & 2.6 & 0.75 & 1.9 & 12 & 15 \\
\hline 4.05 & 1 & 0.3 & 2.3 & 0.55 & 1.3 & 12 & 15 & 4.8 & 1.1 & 0.3 & 2.5 & 0.7 & 1.7 & 12 & 15 \\
\hline 4.25 & 1.1 & 0.3 & 2.4 & 0.65 & 1.5 & 12 & 15 & 4.85 & 1.2 & 0.3 & 2.6 & 0.75 & 1.9 & 11 & 16 \\
\hline 4.25 & 1.1 & 0.3 & 2.3 & 0.65 & 1.7 & 12 & 15 & 4.85 & 1.1 & 0.3 & 2.7 & 0.75 & 2 & 10 & 17 \\
\hline 4.25 & 1 & 0.4 & 2.5 & 0.65 & 1.6 & 12 & 15 & 4.85 & 1.1 & 0.3 & 2.6 & 1.15 & 1.9 & 11 & 16 \\
\hline 4.25 & 1.1 & 0.4 & 2.4 & 0.65 & 1.5 & 12 & 15 & 4.9 & 1.2 & 0.3 & 2.6 & 0.85 & 1.9 & 12 & 15 \\
\hline 4.25 & 1.1 & 0.3 & 2.1 & 0.75 & 1.5 & 12 & 15 & 4.95 & 1.2 & 0.3 & 2.6 & 0.8 & 2 & 10 & 17 \\
\hline 4.25 & 1 & 0.3 & 2.3 & 0.7 & 1.6 & 12 & 15 & 4.95 & 1.2 & 0.3 & 2.7 & 0.85 & 1.9 & 10 & 17 \\
\hline & & & & & & & & 4.95 & 1.1 & 0.3 & 2.7 & 0.85 & 2 & 10 & 17 \\
\hline & & & & & & & & 5 & 1.2 & 0.3 & 2.8 & 0.85 & 2 & 10 & 17 \\
\hline & & & & & & & & 5.1 & 1.1 & 0.3 & 2.7 & 0.8 & 2 & 10 & 17 \\
\hline & & & & & & & & 5.1 & 1.1 & 0.3 & 2.8 & 0.8 & 2 & 10 & 17 \\
\hline
\end{tabular}

(about 6 to 7 melanophores) is on the dorsal midline; and the third (about 14 melanophores) is on the lateral midline of the body. New pigmentation also appears on the head: two dorsal melanophores, a second melanophore in the otic vesicle region, and another pair on the cheek (Fig. 2d).

\section{Unpaired fin formation}

The caudal fin is the first one formed at the onset of flexion, followed by the anal fin, and almost immediately after, the second dorsal fin appears (near $4.5 \mathrm{~mm} \mathrm{SL}$ ). The middle rays of the caudal fin start forming slightly before the beginning of notochord flexion, forming its principal rays slightly after the notochord flexion $(5.1 \mathrm{~mm} \mathrm{SL})$. The anal fin is completed at approximately $8.2 \mathrm{~mm}$ SL. The second dorsal fin is complete at about $9.4 \mathrm{~mm} \mathrm{SL}$ when the first two spines of the first dorsal fin appear. The spinous dorsal fin is completed at the end of the larval period $(\sim 14.2 \mathrm{~mm} \mathrm{SL})$.

\section{Paired fins formation}

The pectoral fin fold is present in the smallest larvae (2.75 mm SL), but rays do not begin formation until 8

$\mathrm{mm} \mathrm{SL}$, and they are fully complete at $12.75 \mathrm{~mm}$ SL. The pelvic fin buds appear at $7.2 \mathrm{~mm} \mathrm{SL}$, and its rays end their formation possibly near the end of the larval period.

\section{DISCUSSION}

To date, only larvae of Microgobius thalassinus, $M$. gulosus and M. meeki that inhabit the Atlantic Ocean have been described by Fritzsche (1978), Yeung \& Ruple (2006), and Teixeira de Farias (2017). These three studies were the basis for all comparisons with the species of this genus used in the present study. These three species share with $M$. tabogensis the presence of one melanophore over the lower angle of the jaw, pigmentation on the dorsal surface of the swim bladder, two to three melanophores along the precaudal ventral midline after the cleithral symphysis, one dorsal melanophore on the hindgut, a series of postanal melanophores along the ventral midline that may form a continuous line during preflexion, the presence of a larger stellate melanophore near the end of the anal fin, and distinct ventral deflection of the hindgut. 
Table 3. Measurements $(\mathrm{mm})$ and the number of preanal (PrA) and postanal (PoA) myomer of postflexion larvae of Microgobius tabogensis. SL: standard length, HL: head length, ED: eye diameter, PrL: preanal length, BDp: pectoral body depth, SBL: swim bladder length, ND: not determined.

\begin{tabular}{|c|c|c|c|c|c|c|c|c|c|c|c|c|c|c|c|}
\hline \multicolumn{6}{|c|}{ Postflexion stage } & \multicolumn{2}{|c|}{ Myomers } & \multicolumn{6}{|c|}{ Postflexion stage } & \multicolumn{2}{|c|}{ Myomers } \\
\hline SL & $\mathrm{HL}$ & ED & PrL & $\mathrm{BDp}$ & SBL & $\operatorname{PrA}$ & PoA & SL & $\mathrm{HL}$ & ED & PrL & $\mathrm{BDp}$ & SBL & $\operatorname{PrA}$ & PoA \\
\hline 5.2 & 1.1 & 0.4 & 2.7 & 1.15 & 2 & 11 & 16 & 7 & 1.5 & 0.4 & 3.7 & 1.1 & 2.8 & 9 & 18 \\
\hline 5.2 & 1.2 & 0.3 & 2.8 & 0.85 & 2 & 10 & 17 & 7 & 1.5 & 0.4 & 3.5 & 1.05 & 2.6 & 10 & 17 \\
\hline 5.3 & 1.3 & 0.3 & 2.9 & 0.9 & 2 & 10 & 17 & 7.2 & 1.6 & 0.4 & 3.8 & 1.15 & 2.8 & 10 & 17 \\
\hline 5.3 & 1.1 & 0.4 & 2.8 & 0.85 & 2 & 10 & 17 & 7.55 & 1.7 & 0.5 & 4 & 1.2 & 3 & 10 & 17 \\
\hline 5.3 & 1.2 & 0.3 & 2.9 & 0.85 & 2 & 10 & 17 & 7.6 & 1.8 & 0.5 & 4.1 & 1.1 & 3 & 9 & 18 \\
\hline 5.35 & 1.2 & 0.4 & 2.9 & 0.9 & 2.1 & 10 & 17 & 7.6 & 1.7 & 0.4 & 4 & 1.15 & 3 & 9 & 18 \\
\hline 5.6 & 1.3 & 0.4 & 3.1 & 0.95 & 2.2 & 10 & 17 & 7.7 & 2.4 & 0.5 & 4.3 & 1.35 & 3.2 & 10 & 17 \\
\hline 5.65 & 1.3 & 0.4 & 3.1 & 0.85 & 2.6 & 10 & 17 & 7.7 & 1.8 & 0.4 & 4.1 & 1.5 & 3.1 & 9 & 18 \\
\hline 5.85 & 1.4 & 0.4 & 3.1 & 0.9 & 2.3 & 10 & 17 & 7.7 & 1.7 & 0.5 & 4 & 1.2 & 3 & 10 & 17 \\
\hline 5.85 & 1.4 & 0.4 & 3.1 & 0.95 & 2.3 & 10 & 17 & 7.8 & 1.7 & 0.4 & 4.1 & 1.25 & 3 & 10 & 17 \\
\hline 5.95 & 1.4 & 0.4 & 3.1 & 0.95 & 2.2 & 10 & 17 & 7.8 & 2.3 & 0.4 & 4.1 & 1.25 & 3.1 & 10 & 17 \\
\hline 5.95 & 1.4 & 0.4 & 3.1 & 1 & 2.2 & 10 & 17 & 8 & 1.8 & 0.5 & 4.1 & 1.65 & 3.2 & 9 & 18 \\
\hline 6 & 1.3 & 0.4 & 3.3 & 0.95 & 2.3 & 12 & 15 & 8.2 & 1.9 & 0.5 & 4.4 & 1.35 & 3.2 & 9 & 18 \\
\hline 6 & 1.3 & 0.4 & 3.2 & 1 & 2.3 & 10 & 17 & 8.4 & 1.8 & 0.5 & 4.4 & 1.35 & 3.3 & 9 & 18 \\
\hline 6 & 1.3 & 0.4 & 3.3 & 1.1 & 2.5 & 10 & 17 & 9.4 & 2.2 & 0.5 & 5 & 1.55 & 3.6 & 9 & 18 \\
\hline 6.05 & 1.3 & 0.4 & 3.3 & 1 & 2.1 & 10 & 17 & 10.3 & 2.3 & 0.6 & 5.8 & 1.85 & 4 & 9 & 18 \\
\hline 6.05 & 1.4 & 0.4 & 3.3 & 1 & 2.4 & 10 & 17 & 10.35 & 2.4 & 0.6 & 5.5 & 1.8 & 4.2 & 9 & 18 \\
\hline 6.15 & 1.3 & 0.4 & 3.3 & 0.95 & 2.4 & 10 & 17 & 11.35 & 3.6 & 0.7 & 6 & 1.95 & 4.4 & 8 & 19 \\
\hline 6.2 & 1.4 & 0.4 & 3.4 & 1.05 & 2.5 & 10 & 17 & 11.35 & 3.3 & 0.7 & 6.1 & 1.95 & 4.6 & 9 & 18 \\
\hline 6.4 & 1.5 & 0.4 & 3.4 & 1 & 2.5 & 9 & 18 & 11.65 & 3.2 & 0.8 & 6.5 & 2.15 & 4.7 & 9 & 18 \\
\hline 6.4 & 1.5 & 0.4 & 3.2 & 1.1 & 2.2 & 9 & 18 & 11.9 & 4 & 0.8 & 6.4 & 2.05 & 4.6 & 9 & 18 \\
\hline 6.45 & 1.6 & 0.4 & 3.5 & 1.15 & 2.5 & 9 & 18 & 12.75 & 3.5 & 0.9 & 7.1 & 2.4 & 4.8 & 9 & 18 \\
\hline 6.7 & 1.5 & 0.4 & 3.8 & 1.05 & 2.8 & 10 & 17 & 14.2 & 3.6 & 1 & 7.5 & 2.4 & 5.4 & ND & ND \\
\hline
\end{tabular}

Table 4. Mean and standard deviation of the body proportions of Microgobius tabogensis for each stage of larval development. n: number of specimens, HL: head length, SL: standard length, ED: eye diameter, PrL: preanal length, BDp: pectoral body depth, SBL: swim bladder length. $\mathrm{ED} / \mathrm{HL}\left(\mathrm{H}_{(2,70)}=33.124, P=6.416 \mathrm{e}^{-08}\right)$ and $\mathrm{SBL} / \mathrm{SL}\left(\mathrm{F}_{(2,113)}=0.122 ; P=\right.$ $\left.5.76 \mathrm{e}^{-15}\right)$.

\begin{tabular}{lcccccc}
\hline & $\mathrm{n}$ & $\mathrm{HL} / \mathrm{SL} \%$ & $\mathrm{PrL} / \mathrm{SL} \%$ & $\mathrm{BDp} / \mathrm{SL} \%$ & $\mathrm{ED} / \mathrm{HL} \%$ & SBL/SL \% \\
\hline Preflexion & 21 & $52.45 \pm 2.53$ & $52.45 \pm 2.53$ & $17.00 \pm 1.75$ & $30.04 \pm 4.42$ & $34.04 \pm 3.11$ \\
Flexion & 25 & $53.55 \pm 1.69$ & $53.55 \pm 1.69$ & $16.79 \pm 2.90$ & $27.52 \pm 2.51$ & $37.47 \pm 2.09$ \\
Postflexion & 70 & $53.37 \pm 1.49$ & $53.37 \pm 1.49$ & $16.77 \pm 1.45$ & $24.68 \pm 3.17$ & $38.91 \pm 1.66$ \\
\hline
\end{tabular}

Although the pigmentation patterns are similar among the described species of this genus, they differ in the developmental stages in which they appear. For example, $M$. tabogensis has pigments in the otic capsule only in postflexion larvae $(8.7 \mathrm{~mm} \mathrm{SL})$, while in M. gulosus, they are present from early flexion to postflexion (4.4 to $8.3 \mathrm{~mm} \mathrm{SL}$ ) and absent in $M$. thalassinus and $M$. meeki. One dorsal melanophore of the tail is present from the preflexion to the early flexion stage in M. tabogensis, while in M. gulosus, it is evident from preflexion to postflexion and absent in M. thalassinus and M meeki. Melanophores located in the cephalic midline and cheeks appear in M. gulosus at $5.1 \mathrm{~mm}$ SL, while in M. tabogensis they are evident at a larger size ( $8.5 \mathrm{~mm} \mathrm{SL})$ and absent in M. thalassinus and $M$. meeki. The pigments located along the base of some lower rays of the tail fin appear earlier in M. meeki (preflexion and flexion) and are much broader and intense in their coloration, followed by $M$. tabogensis (flexion stages until postflexion). In M. thalassinus and M. gulosus, they are observed up to the postflexion stage.

The pigmentation of the tail on its ventral margin is similar in M. gulosus, M. thalassinus, and M. tabogensis, while in $M$. meeki, it presents continuous dendritic pigmentation and intense coloration. The largest dendritic pigment near the end of the anal fin is present in the four species throughout all developmental stages. In M. gulosus, there is also a dendritic pigment in the first third of the anal fin, from flexion to postflexion, 
which is absent in M. tabogensis, M. thalassinus, and M. meeki. The dorsal melanophore of the tail is present in M. gulosus from preflexion to postflexion larvae. $M$. tabogensis is only present in preflexion to early flexion larvae, while $M$. thalassinus and $M$. meeki lack this pigment throughout their development. A series of 1-3 melanophores are located on the ventral margin of the caudal peduncle in flexion and postflexion stages of $M$. gulosus, M. thalassinus, and M. meeki but are absent in M. tabogensis. The postflexion larvae of M. tabogensis and $M$. gulosus can be distinguished by having pigments on the cheek and along the dorsal margin, from the head to the insertion of the dorsal fin, which is absent in M. thalassinus and M. meeki.

The developmental sequence of the paired fin elements is similar in all cases. The pelvic fins begin their development at $7.2 \mathrm{~mm} \mathrm{SL}$ in M. tabogensis and M. gulosus and $7.3 \mathrm{~mm}$ SL in M. thalassinus; for $M$. meeki, it has not been defined. The end of their development coincides with the completion of the complement pectoral fin radii at $10.0 \mathrm{~mm}$ SL in $M$. meeki, $11.0 \mathrm{~mm}$ SL in M. thalassinus, $11.5 \mathrm{~mm} \mathrm{SL}$ in M. gulosus, and $12.75 \mathrm{~mm} \mathrm{SL}$ in $M$. tabogensis (Fritzsche 1978, Yeung \& Ruple 2006, Teixeira de Farias 2017).

The development of odd fins is also similar. The tail fin is the first to complete its formation in all four species $(5.1 \mathrm{~mm} \mathrm{SL} \mathrm{in} \mathrm{M.} \mathrm{tabogensis,} 5.2 \mathrm{~mm} \mathrm{SL}$ in $M$. thalassinus, $6.0 \mathrm{~mm} \mathrm{SL}$ in $M$. meeki, and at $6.5 \mathrm{~mm} \mathrm{SL}$ in $M$. gulosus). The complete development of the first dorsal fin (seven spines) occurs at $8.4 \mathrm{~mm}$ SL in $M$. thalassinus, $9.8 \mathrm{~mm}$ SL in $M$. meeki, $11.5 \mathrm{~mm}$ SL in $M$. gulosus, and $14.2 \mathrm{~mm}$ SL in M. tabogensis. The anal and second dorsal fins finish their formation simultaneously in $M$. thalassinus (8.4 mm SL), $M$. gulosus ( $8.5 \mathrm{~mm} \mathrm{SL})$, and M. meeki (9.1 $\mathrm{mm} \mathrm{SL})$, while in M. tabogensis the anal fin completes its formation at $8.2 \mathrm{~mm} \mathrm{SL}$ and the second dorsal fin at $9.4 \mathrm{~mm} \mathrm{SL}$. These size differences suggest that $M$. tabogensis transforms and settles to a larger size than the other three species.

Although the record of meristic, morphological, and pigmentation characteristics are similar to the larvae of M. gulosus, M. thalassinus, and M. meeki from the Atlantic Ocean, there are notable differences between preflexion and postflexion larvae. Moreover, M. meeki has more noticeable and intense pigmentation in the general pigmentation pattern, and M. gulosus has an additional distinctive dendritic melanophore in the first third of the anal fin base. M. thalassinus lacks two melanophores, the one in the lower angle of the mandible and the dorsal melanophore in the postanal region. Therefore, having compared $M$. tabogensis with its congeners from the Atlantic Ocean, solid evidence shows that a general pigmentation pattern changes throughout larval development. The absence or appearance of some melanophores is of great importance in the differentiation of larvae between species.

Since the pigmentation pattern between $M$. tabogensis and its congeners in the Atlantic Ocean are similar, it can be expected that the pigmentation pattern of the five species yet to be described in the Pacific will also be similar. Recognition of the species of this genus added to the meristic characteristics of the remaining five species would allow their specific recognition since $M$. brevispinis has a greater number of rays in the dorsal and anal fins (18), and M. cyclolepis has the greatest number of rays in the pectoral fin (24), as well as the greatest number of gills rakers in the first arch $(5+16)$. M. emblematicus has the least number of rays on the pectoral fin and 4-5 teeth in the dentary. $M$. erectus has the dorsal and anal fins with the lowest ray number (13) and the lowest number of gills rakers on the first arch (3+13).

M. miraflorensis has the largest number of teeth in the dentary (15-20). Fundamental information is needed to link the adult regressive sequence with the earliest larvae stages (postflexion to preflexion).

In the northwest region of the Mexican Pacific (Magdalena Bay to Sinaloa, including the Gulf of California), the Gobiidae family is represented by 56 species in 29 genera (Birdsong 1981, Birdsong et al. 1988, Allen \& Roberson 1994, Hoese 1995, Watson 1996, Roberson \& Allen 2015). These species can be separated into groups according to the number of vertebrae. For example, 12 species with 30 or more vertebrae; 4 species with 28 vertebrae; 1 species with 27 and 28 vertebrae; 2 species with 26 to 28 vertebrae; 2 species with 26 to 27 vertebrae; 25 species with 27 vertebrae (where the genus Microgobius is found); and 10 species with 26 vertebrae. The combination of vertebrae number with the number of spines and rays of the dorsal, anal, and pectoral fins segregates the Microgobius species complex by presenting the largest number of elements in the dorsal fin (VII; I, 14 to 19), anal fin (I, 13 to 18), and pectoral fin (18 to 24), which represent notable differences with the remaining 50 species that typically have the smallest number of elements in the second dorsal fin and anal fin.

The identification and taxonomic differentiation of fish larvae of the Gobiidae family in zooplankton collections from different seas of the world are complex and require the combination of their morphometric, meristic, and pigmentation characteristics (Kendall et al. 1984, Watson 1996, Leis \& Carson-Ewart 2004, Yeung \& Ruple 2006, González-Navarro et al. 2014). In zooplankton samples, Gobiidae larvae in the preflexion and flexion stages are the most common and 
have the greatest similarity between species in general, making larval stage descriptions difficult.

From the total Gobiidae species registered in the northwest region of the Mexican Pacific, only 13 had been described (most from preflexion to postflexion). Nine species have 30 or more vertebrae and four species 26-27 vertebrae (Watson 1996, GonzálezNavarro et al. 2014). The larvae of M. tabogensis have 27 total myomers and an intestine without pigments on its dorsal margin, which is straight in its first two-thirds and curved in its posterior portion. These characteristics make it different from species with 30 or more vertebrae that have a more extended intestine with pigmentation on the dorsal margin, such as Acanthogobius flavimanus and Clevelandia ios with a row of 12 pigments, Ilipnus gilberti and Lepidogobius lepidus with a row of 2 pigments, Quietula y-cauda and Evermannia zosterura with a row of 3 pigments, Eucyclogobius newberry and Gillichthys mirabilis with a row of 4-6 pigments. Typhogobius californiensis with a continuous row of pigments (Watson 1996).

In contrast with those larvae having 26 to 27 vertebrae, $M$. tabogensis does not present a melanophore series on the dorsal margin at the postanal region. For example, Lytrypnus dalli has a row of 7-12 pigments (myomers, 2-4 to 11-13), and Lytrypnus zebra has a row of 5-8 pigments (myomers, 5-6 to 11-12). Rhinogobiops nicholsii has a row of pigments on the postanal dorsal margin (myomers, 21-25) and extends anteriorly to the postanal myomer-1 presents a continuous row of pigments on the intestine and gas bladder. Gobulus crescentalis has 1-2 (large) melanophores in the ventral postanal margin and 8-12 myomers (usually 9-11) and lacks pigment at the base of the lower rays of the caudal fin and in the otic vesicle in preflexion and flexion larvae (Watson 1996).

The determination of the general pigmentation patterns in the early development of fish, as in the genera Microgobius and Lytrypnus of the Gobiidae family, is of great relevant characteristics. It is possible to consolidate series of larval development for species that we do not know. For this reason, it is essential to continue with larval descriptions to confirm these pigmentation patterns, which can be used to corroborate or refute the preliminary groupings of gobiids established by Birdsong et al. (1988) through the formula of the dorsal and anal and osteological fins between the precaudal and caudal vertebrae.

\section{ACKNOWLEDGMENTS}

Thanks to the Zooplankton Laboratory group (UABCS) for their help in field sampling. GAM thanks Sistema
Nacional de Investigadores. GAM and RJSM thank the Comisión de Operación y Fomento de Actividades Académicas and Estímulo al Desempeño de Investigación. Projects IPN-SIP 20200686, SIP-IPN 20211337, and DIGICSA-SEP 82-04-290 supported this research.

\section{REFERENCES}

Aceves-Medina, G., Inda-Díaz, E., Hernández-Almeida, O.U. \& Álvarez-Ramírez, I.M. 2020. Revisión de algunos aspectos de las primeras fases de vida en los peces marinos y sus implicaciones en la distribución biogeográfica. CICIMAR Oceánides, 35: 1-16.

Aceves-Medina, G., Saldierna-Martínez, R., HinojosaMedina, A., Jiménez-Rosenberg, S.P., HernándezRivas, M.E. \& Morales-Ávila, R. 2008. Vertical structure of larval fish assemblages during diel cycles in summer and winter in the southern part of Bahía de La Paz, México. Estuarine, Coastal and Shelf Science, 76: 889-901. doi: 10.1016/j.ecss.2007.08.016

Agorreta, A., San Mauro, D., Schliewen, U., Van Tassell, J.L., Kovačić, M.Z., Zardoya, R. \& Rüber, L. 2013. Molecular phylogenetics of Gobioidei and phylogenetic placement of European gobies. Molecular Phylogenetics and Evolution, 69: 619-633. doi: 10.1016/ j.ympev.2013.07.017

Ahlstrom, E.H., Butler, J.L. \& Sumida, B.Y. 1976. Pelagic stromateoid fishes (Pisces: Perciformes), of the Eastern Pacific: kinds, distributions, and early life histories and observations on five of these forms from Northwest Atlantic. Bulletin of Marine Science, 26: 285-402.

Allen, G.R. \& Roberson, D.R. 1994. Fishes of the tropical Eastern Pacific. University of Hawaii Press, Honolulu.

Baldwin, C.C. \& Smith, D.G. 2003. Larval Gobiidae (Teleostei: Perciformes) of Carrie Bow Cay, Belize, Central America. Bulletin of Marine Science, 72: 639674.

Birdsong, R.S. 1981. A review of the gobiid fish genus Microgobius Poey. Bulletin of Marine Science, 31: 267-306.

Birdsong, R.S., Murdy, E.O. \& Pezold, F.L. 1988. A study of the vertebral column and median fin osteology in gobioid fishes with comments on gobioid relationships. Bulletin of Marine Science, 42: 174-214.

Fritzsche, R.A. 1978. Development of fishes of the MidAtlantic bight. An atlas on egg, larval and juvenile stages. Vol. V. Chaetodontidae through Ophidiidae. US Fish and Wildlife Service, Arlington.

González-Navarro, E., Saldierna-Martínez, R.J. \& AcevesMedina, G. 2014. Larval development of Evermannia zosterura (Perciformes: Gobiidae). Revista de Biología Tropical, 62: 611-625. 
Guyah, N., Webber, M. \& Prospere, K. 2021. An assessment of the larval fish diversity within a coastal marine reserve: larval fish diversity within a marine reserve. Regional Studies in Marine Science, 43: 101655. doi: 10.1016/j.rsma.2021.101655

Hildebrand, S.F. \& Cable, L.E. 1938. Further notes on the development and life history of some teleosts at Beaufort, N.C. US Bulletin of the Bureau Fisheries, 24: 505-642.

Hoese, D.F. 1995 Gobiidae. In: Fischer, W., Krupp, F., Schneider, W., Sommer, C., Carpenter, K.E. \& Niem, V.H. (Eds.). Guía FAO para la identificación de especies para los fines de la pesca. Pacífico centrooriental. Vol. II. Vertebrados-parte 1. FAO, Roma, pp. 1129-1135.

Kendall Jr., A.W., Ahlstrom, E.H. \& Moser, H.G. 1984. Early life-history stage of fishes and their characteristics. In: Moser, H.G., Richards, W.J., Cohen, D.M., Fahay, M.P., Kendall Jr., A.W. \& Richardson, S.L. (Eds.). Ontogeny and systematics of fishes. American Society of Ichthyologists and Herpetologists, Kansas, pp. 11-22.

Leis, J.M. \& Carson-Ewart, B.M. 2004. The larvae of Indo-Pacific coastal fishes: an identification guide to marine fish larvae. In: Leis, J.M. \& Carson-Ewart, B.M. (Eds.). Fauna Malesiana Handbook 2. Brill, Boston.

Matarese, A.C., Kendall, A.W., Blood, D.M. \& Vinter, B.M. 1989. Laboratory guide of early stages of Northeast Pacific fishes. NOAA Technical Report, National Marine Fisheries Service, 80.

Patzner, R., Van Tassell, J.L., Kovacic, M. \& Kapoor, B.G. 2011. The biology of gobies. CRC Press, Boca Raton.

Potthoff, T. 1984. Clearing and staining techniques. In: Moser, H.G., Richards, W.J., Cohen, D.M., Fahay, M.P., Kendall, A.W. \& Richardson S.L. (Eds.). Ontogeny and systematics of fishes. American Society of Ichthyology and Herpetology, Kansas, pp. 35-37.

R Core Team. 2016. R: a language and environment for statistical computing. R Foundation for Statistical Computing, Vienna. [https://www.R-project.org/]. Reviewed: September 4, 2020.

Richardson, S.L. \& Joseph, E.B. 1975. Occurrence of larvae of the green goby, Microgobius thalassinus, in the York River, Virginia. Chesapeake Science, 16: 215-218.

Roberson, D.R. \& Allen, G.R. 2015. Shorefishes of the Tropical Eastern Pacific online information system. Version 2.0 Smithsonian Tropical Research Institute, Balboa. [https://biogeodb.stri.si.edu/sftep/es/pages]. Reviewed: September 2, 2020.

Received: 26 October 2020; Accepted: 20 April 2021
Ruple, D. 1984. Gobioidei: development. In: Moser, H.G., Richards, W.J., Cohen, D.M., Fahay, M.P., Kendall, A.W. \& Richardson S.L. (Eds.). Ontogeny and systematics of fishes. American Society of Ichthyology and Herpetology, Kansas, pp. 582-587.

Smith, D.G. \& Baldwin, C.C. 1999. Psilotris amblyrhynchus, a new seven-spined goby (Teleostei: Gobiidae) from Belize, with notes on settlement-stage larvae. Proceedings of the Biological Society of Washington, 112: 433-442.

Teixeira de Farias, W.K. 2017. Desenvolvimento ontogenético e ecologia das larvas de Microgobius meeki no Complexo Estuarino de Rio Formoso, Pernambuco. Master's Thesis, Universidade Federal de Pernambuco, Permambuco.

Thacker, C.E. \& Hardman, M.A. 2005. Molecular phylogeny of basal gobioid fishes: Rhyacichthyidae, Odontobutidae, Xenisthmidae, Eleotridae (Teleostei: Perciformes: Gobioidei). Molecular Phylogenetics and Evolution, 37: 858-871. doi: 10.1016/j.ympev.2005. 05.004

Thacker, C.E. \& Roje, D.M. 2011. Phylogeny of Gobiidae and identification of gobiid lineages. Systematics Biodiversity, 9: 329-347. doi: 10.1080/14772000.2011. 629011

Tran, T.T., Tran, H.D. \& Nguyen, H.X. 2018. Larval description and habitat utilization of an amphidromous goby, Redigobius bikolanus (Gobiidae). Animal Biology, 68: 15-26. doi: 10.1163/15707563-17000079

Urias-Leyva, H., Aceves-Medina, G., Avendaño-Ibarra, R., Saldierna-Martínez, R.J., Gómez-Gutiérrez, J. \& Robinson, C.J. 2018. Regionalization in the distribution of larval fish assemblages during winter and autumn in the Gulf of California. Latin American Journal of Aquatic Research, 46: 20-36. doi: 10.3856/ vol46-issue1-fulltext-4

Yeung, C. \& Ruple, D. 2006. Gobiidae. In: Richards, W. (Ed.). Early stages of Atlantic fishes. CRC Press, Boca Raton.

Watson, W. 1996. Gobiidae. In: Moser, H.G. (Ed.). The early stages of fishes in the California Current Region. Atlas 33. California Cooperative Oceanic Fisheries Investigations. Allen Press, Kansas, pp. 1214-1245.

Zacardi, D.M., Santos, J.A.D., Oliveira, L.S.D., Cajado, R.A. \& Pompeu, P.S. 2020. Ichthyoplankton studies as referential for the management and monitoring of fishery resources in the Brazilian Amazon basin. Acta Limnologica Brasiliensia, 32. doi: 10.1590/s2179$975 \times 6619$

Zavala, G.F., Flores, C. \& Méndez, M.L. 1988. Desarrollo y distribución larvaria de Gobiosoma robustum Ginsburg (Pisces: Gobiidae). Laguna de Términos, Campeche. Anuario del Instituto de Ciencias del Mar y Limnología, 15: 237-244. 